\title{
Genetic Information: Comparing Alternative Regulatory Approaches when Prevention Matters*
}

\author{
Francesca Barigozzi ${ }^{\dagger}$ and Dominique Henriet ${ }^{\ddagger}$
}

This version: December 2008

\begin{abstract}
We compare the alternative approaches for regulating genetic information in the health insurance market when prevention measures are available. In the model, firms offer insurance contracts to consumers who are initially uninformed of their risk type but can obtain such information by performing a costless genetic test. A crucial ingredient of our analysis is that information has decision-making value since it allows for optimal choice of a self-insurance action (secondary prevention). We focus on the welfare properties of market equilibria obtained under the different regulatory schemes and, by using an intuitive graphical analysis, we rank them unambiguously.

Our results show that Disclosure Duty weakly dominates the other regulatory schemes and that Strict Prohibition represents the worst regulatory approach.
\end{abstract}

Keywords: health insurance markets, information gathering, discrimination risk, classification risk, self-insurance.

JEL classification: D82; D83; G22; L52.

\section{Introduction}

Recent developments in medical science make genetic testing for more than 1000 diseases available to consumers. Genes that imply an elevated risk of several types of cancer, cardiovascular diseases, Alzheimer's and Huntington's disease, cystic fibrosis, etc. can be detected. Whenever consumers undertake a test they acquire more precise information on the probability that the illness related to

\footnotetext{
${ }^{*}$ The authors are grateful to Giacomo Calzolari, Liqun Liu, Wolf Rogowski, Katharina Fischer and seminar participants in Bologna, Cagliari, London, Milan, Rome and Toulouse for helpful comments and discussions.

${ }^{\dagger}$ Department of Economics, University of Bologna and CHILD, P.zza Scaravilli 2, 40126 Bologna (Italy). E-mail: francesca.barigozzi@unibo.it

¥Department of Economics, Ecole Centrale Marseille, GREQAM and IDEP. E-mail: dominique.henriet@ec-marseille.fr
} 
the tested gene will occur. This means that individuals can learn information about their risk. If privacy rules are in place to keep such information private, adverse selection can arise endogenously in the health insurance market.

In the ongoing debate on the use of genetic information in insurance markets (illustrated, for example, in Hoy and Ruse 2005) insurance firms are worried that adverse selection and related inefficiencies will increase if consumers can secretly take a genetic test and conceal its result. On the other hand, consumers fear that a class of potentially uninsurable individuals, the "bad genetic risks", will be created if insurers can oblige consumers to take a genetic test before policy purchase. This problem is generally referred to as the "discrimination risk". However, both consumers and insurers agree that individuals should not lose, because of their fear of the discrimination risk, the important prevention opportunities offered by genetic information.

As regards prevention opportunities, our model considers secondary prevention measures (early detection of disease). The efficacy of secondary prevention choices is increasing in the precision of information about the risk of illness (the higher the consumers' risk, the higher the benefits they obtain from prevention). Secondary prevention corresponds to a self-insurance measure because it reduces the health loss when the illness occurs. As an example, we can consider the BRCA1 and BRCA2 genetic mutations which are implicated in many hereditary breast cancer cases and the genetic mutation responsible for hereditary non-polyposis colorectal cancer (HNPCC). An individual who is positive to a genetic test for one of the mentioned mutations should more frequently perform screening measures such as mammography and colonoscopy to detect the illness at an early stage. While some authors have investigated the case of primary prevention, that is the availability of measures reducing the probability of illness (see Doherty and Posey 1998, Strohmenger and Wambach 2000, Hoel and Iversen 2002), no one has analyzed secondary prevention even though an improved efficacy in the use of such a type of prevention probably represents the most important health benefit of genetic testing to consumers.

Many elements affect consumer decisions to learn information about their risk of illness. First, as we already mentioned, genetic information has decisionmaking value since it allows secondary prevention measures to be properly targeted to consumer morbidity. In this sense genetic information is beneficial to consumers. Second, when they gather information, consumers face the risk of learning that they are high-risk and thus information brings with it the risk of paying a high premium (classification risk). Since no coverage for the classification risk is available, genetic information is costly for risk-averse consumers. ${ }^{1}$ Finally, the regulatory scheme for genetic information in place in the health insurance market influences consumer choices, as we will see.

Today four major types of market regulation of genetic information exist (see Viswanathan et al. 2007, Hoy and Ruse 2005 and references within both

\footnotetext{
${ }^{1}$ In the real world (and in our model as well) the health insurance market is not able to provide policies that cover the classification risk, despite the obvious increase in consumer welfare. We discuss a remedy to this issue in subsection 2.3.1.
} 
of them). ${ }^{2}$ They are listed below from no-regulation to the most strict regulatory scheme. (i) "Under a Laissez-Faire approach insurers have full freedom to request new tests and the disclosure of existing tests, and to incorporate test results in underwriting and rating". The previous and the following quoted sentences are taken from Viswanathan et al. (2007), page 68. Laissez-faire is practiced in Australia, Canada, China, Japan, Korea, Ireland, Portugal, Russia, Singapore, Spain and South Africa. (ii) Under the Disclosure Duty approach consumers "have to disclose the results of existing tests, at the insurers' request, but cannot be required to take additional tests". This is true in Germany, New Zealand, and the UK. (iii) Under the Consent Law approach consumers "are not required to divulge genetic tests results. If they do, insurers may use this information", as in the Netherlands and in Switzerland. Finally, (iv) under Strict Prohibition, "insurers cannot request genetic tests, cannot require applicant to provide existing tests results, and cannot use any genetic information in underwriting and rating", as in Austria, Belgium, Denmark, France, Israel, Italy and Norway. In the U.S., the Genetic Information Non-discrimination Act (GINA) was signed into law in May 2008. The bill places restrictions on insurers, banning the use of genetic information in underwriting health insurance policies. ${ }^{3}$ Thus, we can now equate the U.S. approach to Strict Prohibition.

The question of genetic privacy is still hotly debated in many countries, as documented by the recent adoption of GINA in the U.S. and by the ongoing discussion (fall 2008) in Germany where a new law aiming at full prohibition of the use of genetic test results in health insurance has been proposed. ${ }^{4}$ Moreover, most countries seem to converge towards assigning consumers full privacy on genetic information and banning information transmission to insurers (Strict Prohibition). Also, being aware of the current public perception that genetic information is somehow different from other health information ${ }^{5}$, in some countries insurance firms have signed a voluntary moratorium on the use of genetic information in health insurance policies (e.g. in the U.K. and in France).

In this paper we consider a simple model which enables us to analyze and compare the previously mentioned regulatory approaches for genetic information when secondary prevention is available. We characterize market outcomes under the different regulatory structures and derive a complete ranking. We believe such a welfare analysis is worthwhile in the debate on genetic testing to understand which regulatory approach is preferable from a social welfare point of view and whether protecting consumers' privacy on genetic information really

\footnotetext{
${ }^{2}$ A similar list appears in Doherty and Thistle (1996) as regards regulatory schemes concerning HIV testing and insurance.

${ }^{3}$ In general, regulation of genetic information is much stricter in the health than in the life insurance market. The implicit reason is that health insurance is considered a priority for consumers whereas life insurance is not.

${ }^{4}$ This means that Germany is moving from the Disclosure Duty to the Strict Prohibition approach.

5 This is called "genetic exceptionalism" and is due to many reasons. Among them are historical reasons (eugenetics), the potential loss of control over samples and the predominance of predictive genetic tests for monogenetic, very serious diseases (e.g. Huntington's disease). See the European Commission (2004).
} 
increases consumers' welfare and really avoids the discrimination risk. To the best of our knowledge this type of analysis is missing in the literature on genetic testing.

In the model we consider the following timing of actions (in all the regulatory approaches, except in the Laissez-Faire where the order of the first two actions is reversed). First, insurance firms propose contracts to consumers. Second, consumers decide whether to perform a costless genetic test and, possibly, whether to show its result to the insurers. Then consumers accept a contract and, finally, they choose prevention taking as given the insurance policy.

Our results show that from a social welfare point of view, the Disclosure Duty approach weakly dominates all the other regulatory schemes. The LaissezFaire and the Consent Law approaches lead to the same equilibrium allocation. The equilibrium allocation under Strict Prohibition is dominated by all other regulatory schemes. Under Consent Law and Strict Prohibition information always has positive private value, whereas Disclosure Duty leads to information gathering only when the benefit of better prevention choices prevails over the cost raised by the classification risk. This is precisely why Disclosure Duty maximizes consumers' welfare. When, under Disclosure Duty, information has positive value, this regulatory scheme leads to the same equilibrium allocation as Consent Law and Laissez-Faire. In all the regulatory approaches, when the test is performed, information is disclosed at the equilibrium. Under Consent Law, information is certifiable and it is transmitted at no cost by low-risk consumers showing insurers the test result whereas under Strict Prohibition, screening is obtained through the Rothschild-Stiglitz separating allocation, thus the equilibrium implies a welfare loss since the low-risks receive partial insurance. Strict Prohibition is the only regulatory scheme that endogenously generates adverse selection. As regards prevention choices, when information always has positive private value, that is with Laissez-Faire, Consent Law and Strict Prohibition, choices are always efficient (in a sense that will be specified in the paper) whereas under Disclosure Duty, they are efficient only when consumers learn information.

As is discussed in the concluding section, our results have important policy implications since the most commonly adopted regulatory scheme turns out to be the least efficient one.

As regards the related literature, all the papers dealing with genetic testing are clearly relevant. ${ }^{6}$ However, the papers most closely related to our study analyze endogenous information in insurance markets and are mentioned below. Crocker and Snow (1992) first showed that, if coverage against the classification risk is not available and if insurers can observe both whether consumers performed the test and the test result itself, the private value of information

\footnotetext{
${ }^{6}$ For example, in Hoel and Iversen (2002) genetic information allows better primary prevention measures to be taken and the health insurance market is characterized by a mix of compulsory and voluntary insurance. Hoel et al. (2006) analyze a model where consumers are characterized by preferences for late resolution of uncertainty concerning their health risk. Strohmenger and Wambach (2000) analyze a model with state contingent utility functions. Hoy and Polborn (2000) consider a life insurance model. Interesting empirical analysis can be found in Hoy and Witt (2007), Viswanathan et al. (2007).
} 
is negative and consumers prefer to remain uninformed. Doherty and Thistle (1996) developed a model where some consumers are initially informed on their risk type and others are not. They showed that information has positive private value only when insurers cannot observe consumers' information status, that is if consumers can conceal not only the test result but also the fact that they performed the test. Both when information provided by the test is not verifiable and when the test result is certifiable (that is under Strict Prohibition and Consent Law respectively), at the equilibrium all consumers perform the test. In Doherty and Posey (1998) information has decision-making value. However, as already noted, the latter authors analyze the case of self-protection; we instead consider the case of self-insurance. Moreover, all the previously mentioned authors analyze one or two information structures at most, we instead compare all the alternative regulatory approaches and we are able to rank them unambiguously. Finally our paper is also related to the more general literature on information gathering before contracting (among others Hirshleifer 1971 and Khalil and Cremer 1992) ${ }^{7}$ and, more closely, to the literature on the economics of privacy. In line with the Chicago School approach to the latter issue (for example Stigler 1980 and Posner 1981), our results show that privacy is not welfare improving. In our model this happens because, if privacy is assigned to consumers on their information status and on test results, consumers decide to learn information also when it is inefficient to do so.

Our paper is organized as follows. Section 2 introduces the model set-up and analyses the decision-maker's problem without insurance. Subsection 2.2 describes how insurance coverage affects consumer choices in terms of prevention and defines the interim optimal allocation. Subsection 2.3 shows the ex-ante optimal allocation and discusses how to decentralize such allocation in the market. Both the interim optimal and the ex-ante optimal allocations will be used to rank market outcomes in the subsequent sections. In section 3 market equilibria are obtained and characterized under the different regulatory schemes. In Section 4 we compare the alternative regulatory structures and derive a complete ranking. Section 5 provides some final remarks and discusses policy implications. We relegate almost all the proofs to the appendix.

\section{The model}

Decision-makers are endowed with a fixed amount of wealth $w$, and are characterized by the von Neumann-Morgenstern utility function $u(w)$, increasing and concave. They face the risk of a monetary loss $L(a)$, where $0<L(a)<w$. The action $a$ is a self-insurance measure. By interpreting $L($.$) as the monetary$ equivalent of a negative health shock, the action $a$ refers to secondary prevention or early detection of disease. The action can take only two values, 0 and 1 (either decision-makers perform prevention or not) with $L(1)=l<L(0)=L$. Moreover, the action $a$ is taken before the realization of the risk and implies a

\footnotetext{
${ }^{7}$ See Bennardo (2008) for a recent analysis along these lines.
} 
utility cost $\Psi(a)$, with $\Psi(0)=0$ and $\Psi(1)=\Psi$. In the real world secondary prevention which allows early curative action is generally observable and certifiable; thus, we assume that insurers observe the action $a$. As a consequence, all the insurance contracts analyzed in the paper are contingent on the level of secondary prevention.

We consider two decision-maker types, the high- and the low-risks, respectively characterized by the probability $p_{L}$ and $p_{H}$ of incurring the loss, with $0<p_{L}<p_{H}<1$. We assume that $p_{L}$ and $p_{H}$ are fixed, so that no ex-ante moral hazard problem exists. The proportion of high- and low-risk types in the population is $\lambda$ and $(1-\lambda)$ respectively. These parameters are assumed to be common knowledge.

Consumers do not know their type ex-ante, they perceive their loss probability as $p_{U}=\lambda p_{H}+(1-\lambda) p_{L}$. Information can be gathered without cost by performing a genetic test.

Risk neutral insurance companies propose contracts to consumers. The insurance market is characterized by free entry such that insurance firms earn zero profits in equilibrium. This is why, in our analysis, social welfare corresponds to consumer welfare.

\subsection{The decision-maker's problem without insurance}

In this subsection we focus on the decision whether to gather information when insurance is not available.

Consumers decide whether to learn information or not by anticipating that, in the subsequent stage, they will choose whether to perform prevention given the information they may have acquired.

Proceeding backward, let's consider the second stage, that is the choice of the preventative action. An individual characterized by loss probability $p_{i} \in$ $\left\{p_{L}, p_{U}, p_{H}\right\}$ who chooses action $a$ achieves the following expected utility level:

$$
V\left(p_{i}, a\right)=p_{i} u(w-L(a))+\left(1-p_{i}\right) u(w)-\Psi(a)
$$

The decision-maker chooses a positive amount of prevention if $V\left(p_{i}, 1\right) \geq$ $V\left(p_{i}, 0\right)$, that is if $p_{i} u(w-l)+\left(1-p_{i}\right) u(w)-\Psi \geq p_{i} u(w-L)+\left(1-p_{i}\right) u(w)$, or:

$$
p_{i} \geq \frac{\Psi}{u(w-l)-u(w-L)}=\frac{\Psi}{\Delta_{0}}
$$

The term $\Delta_{0}$ is positive and measures the benefit from prevention. When this term is large and/or the cost of prevention $\Psi$ is low, inequality (1) is easily verified. Put differently, inequality (1) shows that decision-makers choose to perform prevention when their loss probability is sufficiently high.

Remark 1 The uninsured decision-makers choose prevention if inequality (1) holds. This implies that incentives to perform prevention are increasing in the decision-makers' risk. 
Let's define $\widehat{a}\left(p_{i}\right)$ the action chosen by an individual characterized by probability of loss $p_{i}$ and $\widehat{V}\left(p_{i}\right)$ the individual's indirect expected utility when the probability is $p_{i}$ and the chosen action is $\widehat{a}\left(p_{i}\right)$.

In the first stage, uninformed decision-makers compare utility when they remain uninformed to expected utility when they gather information, that is $\hat{V}\left(p_{U}\right)$ to $\lambda \widehat{V}\left(p_{H}\right)+(1-\lambda) \widehat{V}\left(p_{L}\right)$. The following remark illustrates consumer choices about information when insurance is not available.

Remark 2 Without insurance, (i) when prevention is optimal for low-risks $\left(p_{L} \geq \frac{\Psi}{\Delta_{0}}\right)$ or when no-prevention is optimal for high-risks $\left(p_{H} \leq \frac{\Psi}{\Delta_{0}}\right)$, decisionmakers are indifferent between remaining uninformed and gathering information. (ii) When $p_{L}<\frac{\Psi}{\Delta_{0}}<p_{H}$ uninformed decision-makers acquire information on their risk-type.

Proof. See Appendix 6.1.

From 1, when prevention costs are such that the optimal action for informed low-risks is a positive level of prevention, prevention is optimal also for uninformed and informed high-risks. Thus, uninformed individuals are indifferent between acquiring and not acquiring information. The same reasoning applies when informed high-risks choose no-prevention. ${ }^{8}$ On the contrary, when $p_{L}<\frac{\Psi}{\Delta_{0}}<p_{H}$, positive prevention is optimal for high-risks whereas no-prevention is the optimal choice for low-risks. Intuitively, here information is useful for appropriate prevention decisions so that acquiring information is welfare improving. Note that, since no insurance is available, when deciding whether to gather information individuals do not face the classification risk, they simply anticipate the positive effect of information in terms of better prevention choices.

Social welfare when insurance is not available, $W_{0}$, is represented in Figure 1 as a function of prevention cost $\Psi$. Note that, for $0 \leq \Psi \leq \Delta_{0} p_{L}$, both types perform prevention; for $\Delta_{0} p_{L}<\Psi<\Delta_{0} p_{H}$ high-types only perform prevention; for $\Psi \geq \Delta_{0} p_{H}$ no one performs prevention.

We conclude this section by observing that, without insurance, the private and social value of information is positive for $\Delta_{0} p_{L}<\Psi<\Delta_{0} p_{H} \cdot{ }^{9}$ In all the other cases the private and social value of information is zero and decisionmakers are indifferent between remaining uninformed and gathering information.

\section{$2.2 \quad$ Interim optimal insurance}

We analyze here optimal insurance contracts from an interim perspective, that is when decision-makers perform the test and the test result is public informa-

\footnotetext{
${ }^{8}$ Note that, when the action $a$ is not available, uninsured decision-makers are always indifferent between remaining uninformed and learning their type. In other words, without insurance and considering decision-makers uniquely concerned with information gathering, $V\left(p_{U}\right)$ is always equivalent to $\lambda V\left(p_{H}\right)+(1-\lambda) V\left(p_{L}\right)$.

${ }^{9}$ Note that, under the Law of Large Number, consumers' expected utility and social welfare are the same such that the private and social value of information are equivalent.
} 
tion. In the next sub-paragraph we will analyze the ex-ante optimal allocation. Both the ex-ante optimal and the interim optimal allocation will be used to characterize and rank market outcomes under the different regulatory schemes.

In the following $P_{i}$ indicates the insurance premium and $I_{i}$ the indemnity reimbursed in the event of the loss occurring. The optimal contract is hence the solution of the following program:

$$
\left\{\begin{array}{l}
\max _{P_{i}, I_{i}, a_{i}} \quad p_{i} u\left(w-P_{i}-L\left(a_{i}\right)+I_{i}\right)+\left(1-p_{i}\right) u\left(w-P_{i}\right)-\Psi\left(a_{i}\right) \\
\text { s.t.: } \quad P_{i} \geq p_{i} I_{i}
\end{array}\right.
$$

where $i=L, H$. Obviously the optimal contract provides full-insurance: $I_{i}=$ $L\left(a_{i}\right)$ at a fair premium.

Assuming full information, risk neutral insurance firms and free entry, the interim optimal allocation can be decentralized in the market. In such a case consumers choose prevention given the full-insurance contract $\left(p_{i} L\left(a_{i}\right), L\left(a_{i}\right)\right)$. The level $W\left(p_{i}, a\right)$ of utility achieved by a decision-maker characterized by risk $p_{i}$ and action $a$ is:

$$
W\left(p_{i}, a\right)=u\left(w-p_{i} L(a)\right)-\Psi(a)
$$

Prevention is positive if $W\left(p_{i}, 1\right) \geq W\left(p_{i}, 0\right)$ :

$$
u\left(w-p_{i} l\right)-\Psi \geq u\left(w-p_{i} L\right)
$$

or:

$$
\Delta\left(p_{i}\right)=u\left(w-p_{i} l\right)-u\left(w-p_{i} L\right) \geq \Psi
$$

Remark 3 In the interim optimal allocation: (i) prevention is performed if inequality (2) holds; (ii) incentives to perform prevention are increasing in the decision-maker's risk; (iii) given a risk $p_{i}$, incentives to perform prevention are lower than without insurance.

Proof. See Appendix 6.2.

Note that, if $\Delta\left(p_{i}\right)<\Psi \leq p_{i} \Delta_{0}$, type- $p_{i}$ does not exert prevention when fully insured whereas he chooses positive prevention when uninsured. In fact, insurance reduces the benefits from the preventative action and discourages prevention for a given risk.

Total welfare in the interim optimal allocation is:

$W_{I}^{*}=\lambda u\left(w-p_{H} L\left(\tilde{a}\left(p_{H}\right)\right)\right)+(1-\lambda) u\left(w-p_{L} L\left(\tilde{a}\left(p_{L}\right)\right)\right)-\lambda \Psi\left(\tilde{a}\left(p_{H}\right)\right)-(1-\lambda) \Psi\left(\tilde{a}\left(p_{L}\right)\right)$

where $\tilde{a}\left(p_{i}\right)$, the action chosen by an individual characterized by risk $p_{i}$, is 1 if inequality (2) holds and 0 otherwise. From Remark 3:

Definition 1 (Interim optimal allocation) The interim optimal allocation $W_{I}^{*}$ is the allocation such that decision-makers are informed and fully insured. Premium is type-dependent and equal to $\tilde{P}_{i}=p_{i} L\left(\tilde{a}\left(p_{i}\right)\right)$. Moreover:

- when $0 \leq \Psi \leq \Delta\left(p_{L}\right), \tilde{a}\left(p_{L}\right)=\tilde{a}\left(p_{H}\right)=1$. 


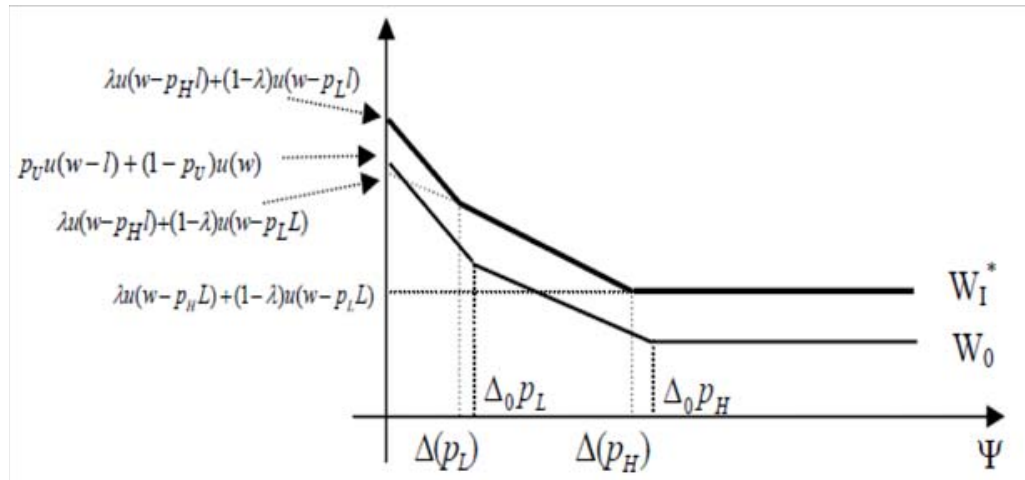

Figure 1: social welfare without insurance $W_{0}$ and the interim optimal allocation $W_{I}^{*}$.

- when $\Delta\left(p_{L}\right)<\Psi \leq \Delta\left(p_{H}\right), \tilde{a}\left(p_{L}\right)=0, \tilde{a}\left(p_{H}\right)=1$.

- when $\Psi>\Delta\left(p_{H}\right), \tilde{a}\left(p_{L}\right)=\tilde{a}\left(p_{H}\right)=0$.

Figure 1 describes total welfare in the interim optimal allocation as a function of the cost of prevention $\Psi$ and offers a graphical representation of expression 3 .

\section{$2.3 \quad E x$-ante optimal insurance (the first-best)}

We now define the ex-ante optimal allocation as the allocation maximizing $e x$ ante expected utility under the feasibility constraint and such that decisionmakers acquire information after the contract is offered. Both coverages for the classification risk and for the risk of the loss are thus available. Everything is observable and contractible.

The first-best contract solves:

$$
\left\{\begin{array}{c}
\max _{P_{H}, I_{H}, P_{L}, I_{L}, a_{H}, a_{L}} \lambda\left(p_{H} u\left(w-P_{H}-L\left(a_{H}\right)+I_{H}\right)+\left(1-p_{H}\right) u\left(w-P_{H}\right)-\Psi\left(a_{H}\right)\right)+ \\
(1-\lambda)\left(p_{L} u\left(w-P_{L}-L\left(a_{L}\right)+I_{L}\right)+\left(1-p_{L}\right) u\left(w-P_{L}\right)-\Psi\left(a_{L}\right)\right) \\
\text { s.t.: } \quad \lambda P_{H}+(1-\lambda) P_{L} \geq \lambda p_{H} I_{H}+(1-\lambda) p_{L} I_{L}
\end{array}\right.
$$

Obviously the first-best implies full insurance: $I_{i}=L\left(a_{i}\right), i=L, H$. Moreover, since the ex-ante optimal insurance covers the classification-risk, the optimal premium is uniform: $P^{*}=\lambda p_{H} L\left(a_{H}\right)+(1-\lambda) p_{L} L\left(a_{L}\right)$.

The optimal prevention decisions, $a_{i}^{*}, i=L, H$, are the solutions of:

$$
\max _{a_{H}, a_{L}} W_{E A}\left(a_{H}, a_{L}\right)=u\left(w-\lambda p_{H} L\left(a_{H}\right)-(1-\lambda) p_{L} L\left(a_{L}\right)\right)-\lambda \Psi\left(a_{H}\right)-(1-\lambda) \Psi\left(a_{L}\right)
$$


Depending on which type performs prevention, four cases are possible:

$$
\begin{aligned}
& W_{E A}^{* 1}=u\left(w-p_{U} l\right)-\Psi \\
& W_{E A}^{* 2}=u\left(w-\lambda p_{H} l-(1-\lambda) p_{L} L\right)-\lambda \Psi \\
& W_{E A}^{* 3}=u\left(w-\lambda p_{H} L-(1-\lambda) p_{L} l\right)-(1-\lambda) \Psi \\
& W_{E A}^{* 4}=u\left(w-p_{U} L\right)
\end{aligned}
$$

Welfare is $W_{E A}^{* 1}\left(W_{E A}^{* 4}\right)$ when both types (no type) perform prevention whereas $W_{E A}^{* 2}$ and $W_{E A}^{* 3}$ correspond to the cases where only high-types and only low-types respectively perform prevention. Between $W_{E A}^{* 2}$ and $W_{E A}^{* 3}$ the most natural case to analyze is the one where prevention is performed by high-types, as in the interim optimal allocation. Thus, we assume that $\forall \Psi, W_{E A}^{* 2} \geq W_{E A}^{* 3}$. It can be easily checked that two sufficient conditions are: (a) $\lambda p_{H} \geq(1-\lambda) p_{L}$, (b) $\lambda \leq(1-\lambda)$. Note that, according to condition (b), the proportion of high-risks in the population must be lower than that of low-risks: $\lambda \leq 1 / 2$. Conditions (a) and (b) together indicate that the loss probability $p_{H}$ must be sufficiently higher than $p_{L}$, in particular $p_{H} \geq \frac{1-\lambda}{\lambda} p_{L}$ where $\frac{1-\lambda}{\lambda} \geq 1 .{ }^{10}$

We define the ex-ante optimal allocation as follows:

Definition 2 (Ex-ante optimal allocation) The first-best $W_{E A}^{*}$ is the allocation such that both the classification risk and the risk of the loss are fully covered. Consumers pay the uniform premium $P^{*}=\lambda p_{H} L\left(a_{H}^{*}\right)+(1-\lambda) p_{L} L\left(a_{L}^{*}\right)$, learn their risk and, under assumption 1, decide whether to perform prevention:

- when $0 \leq \Psi \leq \frac{u\left(w-p_{U} l\right)-u\left(w-\lambda p_{H} l-(1-\lambda) p_{L} L\right)}{1-\lambda}=\Psi_{1}, a_{L}^{*}=a_{H}^{*}=1$.

- when $\Psi_{1} \leq \Psi \leq \frac{u\left(w-\lambda p_{H} l-(1-\lambda) p_{L} L\right)-u\left(w-p_{U} L\right)}{\lambda}=\Psi_{2}, a_{L}^{*}=0, a_{H}^{*}=1$.

- when $\Psi \geq \Psi_{2}, a_{L}^{*}=a_{H}^{*}=0$.

Definition 2 shows that, as in the interim optimal allocation, when the cost of prevention is low both types perform prevention; as the cost of prevention increases only high-types perform prevention; finally, when the cost is sufficiently high, no prevention is performed. Obviously, in the ex-ante and interim optimal allocations, threshold values for $\Psi$ differ. Figure 2 describes social welfare in first-best $W_{E A}^{*}$ as a function of the cost of prevention $\Psi$.

Note that, since in the ex-ante optimal allocation the classification risk is covered whereas in the interim optimal it is not, the ex-ante optimal allocation dominates the interim one.

\footnotetext{
${ }^{10}$ Note that both types pay the same premium irrespective of their action and get (gross) utility $u(w-P)$. When the action chosen by the two types is different, those performing prevention suffer the disutility loss $\Psi$ and receive a lower net utility. In this case the social planner may want to introduce some transfers aiming at redistributing between the two groups the monetary equivalent of prevention cost.
} 


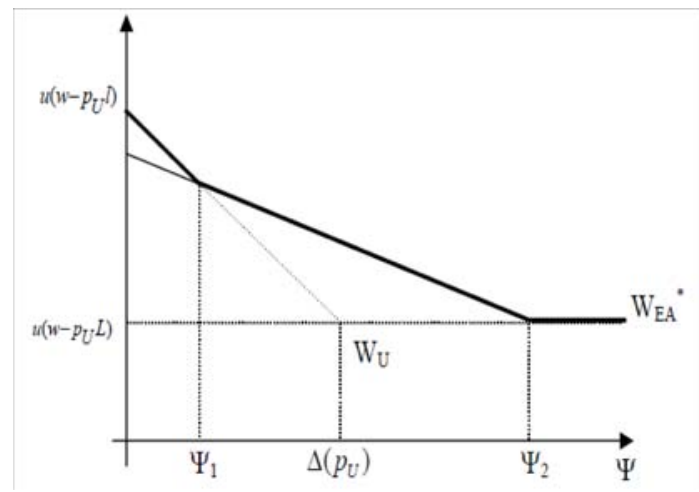

Figure 2: social welfare with full insurance and with no information $W_{U}$ and the ex-ante optimal allocation $W_{E A}^{*}$.

\subsubsection{How to implement the first-best: "genetic insurance"}

Tabarrok (1994), discussing insurance issues related to genetic testing, proposes decentralizing the ex-ante optimal allocation by creating a market selling insurance against the classification risk. Such a policy, "genetic insurance", should be mandatory for those who decide to gather information: information acquisition should be possible only after insurance against classification risk has been purchased. This can be enforced by making it illegal for physicians and laboratories to run tests without proof that genetic insurance has been bought. In this way adverse-selection problems can be avoided.

Let's assume, for the moment, that insurers offer both coverage against the risk of the loss and coverage against the classification risk, and that genetic insurance is mandatory for those who decide to test. Moreover, as before, the insurance market is characterized by free entry. We show below that consumers would purchase genetic insurance and would learn information such that the first best would be implemented. To do this we must compare utility when the test is performed to utility when consumers decide to remain uninformed. Since decision-makers must purchase genetic insurance to learn information, if they decide to test, as in the ex-ante optimal allocation they must pay the premium $P^{*}=\lambda p_{H} L\left(a_{H}^{*}\right)+(1-\lambda) p_{L} L\left(a_{L}^{*}\right)$ (remember that consumers are all equal ex-ante). Moreover, they are committed to performing action $a_{i}^{*}, i=L, H$, whenever the test certifies that the type is $i$, as according to (4). Once genetic insurance has been bought, decision-makers perform the test and exhibit the test result to the insurer. Consumers receive reimbursement $p_{i} L\left(a_{i}^{*}\right)$ and, with that amount, they purchase fair, full insurance against the risk of the loss and choose the optimal action $a_{i}^{*}, i=L, H$. Thus, when genetic insurance is available and consumers decide to learn information, they obtain the first-best utility.

Now we find utility when genetic testing is not performed. The following remark describes social welfare when consumers remain uninformed in the in- 
surance market with free entry:

Remark 4 (The allocation when consumers remain uninformed) Social welfare when consumers remain uninformed is $W_{U}=u\left(w-p_{U} L\left(\tilde{a}\left(p_{U}\right)\right)\right)-$ $\Psi\left(\tilde{a}\left(p_{U}\right)\right)$. Consumers are fully insured and pay the premium $p_{U} L\left(\tilde{a}\left(p_{U}\right)\right)$. Moreover, according to inequality (2): for $\Psi \leq \Delta\left(p_{U}\right), \tilde{a}\left(p_{U}\right)=1$ whereas for $\Psi>\Delta\left(p_{U}\right), \tilde{a}\left(p_{U}\right)=0$.

In Figure 2 utility $W_{U}$ is represented by the dotted kinked line.

Note that, for $\Psi \leq \Psi_{1}$ and $\Psi \geq \Psi_{2}$, in the ex-ante optimal allocation both informed types choose the same action, thus decision-makers are indifferent between learning information and remaining uninformed $\left(W_{U} \equiv W_{E A}^{*}\right)$. On the contrary, for $\Psi_{1}<\Psi<\Psi_{2}, P^{*} \neq p_{U} L\left(\tilde{a}\left(p_{U}\right)\right)$ and $W_{U}$ is dominated by $W_{E A}^{*}$. Obviously this happens since, with information gathering, prevention choices are more efficient.

We can conclude that mandatory genetic insurance allows the first-best to be decentralized. ${ }^{11}$

\section{The insurance market under the alternative regulatory schemes}

Ex-ante all decision-makers are uninformed; they can remain uninformed or they can perform a genetic test. Insurance against classification risk is not available and, in this sense, the market that we consider is inefficient even when adverse selection does not arise. The sequence of actions changes slightly according to the regulatory approach analyzed. We will describe the timing in detail in each of the following subparagraphs, starting with the disclosure duty approach.

\subsection{The Disclosure Duty approach}

Under this regulatory approach decision-makers are obliged to disclose the result of previously performed genetic tests to insurers, but cannot be required to take additional tests. Note that, under both Laissez-Faire and Disclosure Duty, consumers' information status and the test results are observed by insurers. The difference between the two regulatory schemes is that, under Laissez-Faire, the

\footnotetext{
${ }^{11}$ Insurance against the classification risk is also the key element of Cochrane's (1995) "timeconsistent insurance". Time-consistent insurance provides insurance against classification risk as well as insurance against the uncertain component of one period health expenditures. For the implementation of insurance against the classification risk in a dynamic context the author proposes a severance payment: a person whose premium increases (for example because a long-term illness is diagnosed) receives a lump sum equal to the increased present value of his premium. The severance payment scheme compensates for changes in premium and allows every consumer to purchase insurance at his actuarially fair premium.

Apart the fact that we do not consider any dynamic in our model, an important difference with respect to time-consistent insurance is that, in the present framework, consumers decide whether to gather (possibly) private information on their risk, whereas in Cochrane's model information on consumers' risk is always publicly disclosed in each period.
} 
decision whether to perform the test is in practice assigned to insurers, whereas under Disclosure Duty consumers are the decision-makers.

Insurance contracts can be contingent on informational status and risk. The timing of actions is the following: first, insurers propose contracts, then consumers decide whether to perform the test. Insurers observe the consumer decisions and, if the test is performed, its result is disclosed. Consumers then accept a contract and choose prevention.

Insurance firms offer three different types of contract: the full coverage contract for the uninformed, the full coverage contract for informed high-risks and the full coverage contract for informed low-risks. If consumers choose to remain uniformed, they obtain with certainty the full coverage contract for uninformed and achieve the level of utility $W_{U}$ represented in Figure 2 and described in Remark 4. When, on the other hand, decision-makers choose to perform the test, they obtain the full coverage contract for high-risks with probability $\lambda$ and the full coverage contract for low-risks with probability $1-\lambda$. That is, they obtain the interim optimal allocation $W_{I}^{*}$ defined in section 2.2 and represented in Figure 1. Thus, information gathering depends on the comparison between utility when decision-makers remain uninformed $W_{U}$ and expected utility corresponding to the interim optimal allocation $W_{I}^{*}$.

Two antagonistic effects are at stake in determining the relative positions of $W_{U}$ and $W_{I}^{*}$. On the one hand, information gathering results in facing the classification risk and hence has a negative effect on welfare; on the other hand, it allows a more efficient choice of prevention which is beneficial. Intuitively, when the classification risk is not too large $\left(p_{H}-p_{L}\right.$ low) and/or when consumers are not too risk-averse, and/or when the benefits from prevention are high $(L / l$ large), consumers should prefer to perform the test.

It is easy to verify that two cases are possible.

Definition 3 Equilibrium of Type 1 occurs if $W_{U}$ always dominates $W_{I}^{*}$. Equilibrium of Type 2 occurs if $W_{U}$ and $W_{I}^{*}$ cross each other.

Note that, in Equilibrium of Type 2, values of $\Psi$ for which $W_{I}^{*}$ dominates $W_{U}$ exist inside the interval $\left[\Delta\left(p_{L}\right), \Delta\left(p_{H}\right)\right]$ (see the kinked bold line in Figure $3)$. In particular, Remark 5 can be stated given the following inequality:

$$
\frac{\frac{u\left(w-p_{U} l\right)-u\left(w-p_{H} l\right)}{\left(p_{H}-p_{U}\right) l}}{\frac{u\left(w-p_{L} L\right)-u\left(w-p_{U} L\right)}{\left(p_{U}-p_{L}\right) L}}>\frac{L}{l}
$$

Remark 5 Under the Disclosure Duty approach, (i) if inequality (9) is satisfied, expected utility with the test is always dominated by utility without the test; (ii) otherwise, expected utility with the test dominates utility without the test in the interval $\Psi_{3}<\Psi<\Psi_{4}$ and is dominated elsewhere, with:

$$
\begin{aligned}
\Psi_{3} & =\frac{1}{1-\lambda}\left[u\left(w-p_{U} l\right)-\lambda u\left(w-p_{H} l\right)-(1-\lambda) u\left(w-p_{L} L\right)\right] \\
\Psi_{4} & =\frac{1}{\lambda}\left[\lambda u\left(w-p_{H} l\right)+(1-\lambda) u\left(w-p_{L} L\right)-u\left(w-p_{U} L\right)\right]
\end{aligned}
$$




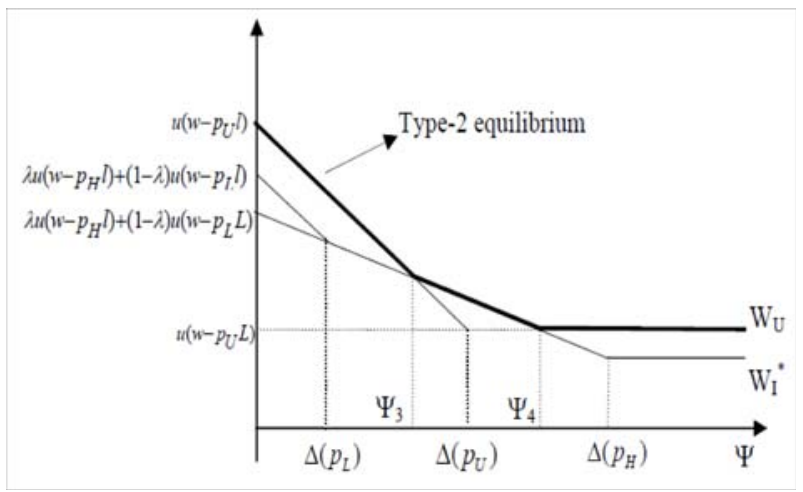

Figure 3: equilibrium allocation under Disclosure Duty when $W_{U}$ and $W_{I}^{*}$ cross each other.

Proof. See Appendix 6.3.

Remark 6 The opposite of inequality (9) is verified if $p_{H}-p_{L}$ is smaller than a threshold increasing function of $L / l$.

Proof. See Appendix 6.4.

The previous remark shows that, when the classification risk is low and/or when the potential gain from prevention is high, decision-makers learn information for $\Psi_{3}<\Psi<\Psi_{4}$ since, in that interval, the gain due to information is larger than the loss due to increased risk. In all the other cases the benefit of information is dominated by the welfare cost caused by the classification risk. ${ }^{12}$

From Remark 5 and from the previous discussion:

Lemma 1 (Equilibrium allocation under Disclosure Duty) Under the Disclosure Duty approach two different equilibria are possible: (i) Equilibrium of Type 1 occurs if inequality (9) holds. At this equilibrium decision-makers always remain uninformed. (ii) Equilibrium of Type 2 occurs if the opposite of inequality (9) holds. At this equilibrium decision-makers perform the test for $\Psi_{3}<\Psi<\Psi_{4}$ and remain uninformed elsewhere.

Croker and Snow (1992) show that, when insurance against the classification risk is not available and insurance firms and consumers have access to the same information, the private value of such information is negative for consumers. Lemma 1 extends Croker and Snow's result to the case where information has decision-making value: when secondary prevention is available, for intermediate

\footnotetext{
${ }^{12}$ Note that the lower the proportion of high-risk in the population $\lambda$, the less negative the slope of the line $\lambda u\left(w-p_{H} l\right)+(1-\lambda) u\left(w-p_{L} L\right)-\lambda \Psi$ (see Figure 3 ), and the higher the probability that $W_{I}^{*}$ and $W_{U}$ cross each other inside the interval $\left[\Delta\left(p_{L}\right), \Delta\left(p_{H}\right)\right]$. In fact a low $\lambda$ implies that social welfare $W_{I}^{*}$ decreases slowly with $\Psi$ when high-risks only perform prevention: close to $\Delta\left(p_{U}\right)$ the social cost of prevention $\lambda \Psi$ is low.
} 
values of prevention cost consumers may prefer to acquire information. In fact, when prevention cost is close to $\Delta\left(p_{U}\right)$ ignorance can make decision-makers' prevention choices very inefficient: for $\Psi_{3} \leq \Psi \leq \Delta\left(p_{U}\right)$ uninformed low-types perform prevention despite prevention cost being too high given their risk and, for $\Delta\left(p_{U}\right) \leq \Psi \leq \Psi_{4}$, uninformed high-types do not perform prevention despite prevention cost being sufficiently low given their risk.

The following corollary summarizes the welfare properties of the equilibrium allocations described in Lemma 1.

Corollary 1 (Welfare properties of equilibrium allocations under Disclosure Duty) When insurance against classification risk is not available and a Disclosure Duty rule is in place: (i) in Type 1 Equilibrium social welfare is $W_{U}$ : with respect to the first-best over-prevention arises for $\Psi_{1}<\Psi \leq \Delta\left(p_{U}\right)$ whereas under-prevention arises for $\Delta\left(p_{U}\right)<\Psi<\Psi_{2}$. (ii) in Type 2 Equilibrium, in the interval $\Psi_{3} \leq \Psi \leq \Psi_{4}$ the interim optimal allocation $W_{I}^{*}$ is reached and prevention choices are interim efficient whereas for $\Psi<\Psi_{3}$ and $\Psi>\Psi_{4}$ social welfare is $W_{U}$ with over-prevention arising for $\Psi_{1}<\Psi<\Psi_{3}$ and under-prevention arising for $\Psi_{4}<\Psi<\Psi_{2}$. (iii) Welfare losses (with respect to the first-best) are lower in Type 2 Equilibrium than in that of Type 1. In both equilibria first-best is reached for $\Psi \leq \Psi_{1}$ and $\Psi \geq \Psi_{2}$.

Proof. (i) The welfare comparison between $W_{U}$ and $W_{E A}^{*}$ can be easily obtained from Figure 2. (ii) The welfare comparison between Equilibrium of type 2 and first-best can be performed by comparing $W_{E A}^{*}$ in Figure 2 with the kinked bold line in Figure 3 and noting that $\Psi_{1}<\Psi_{3}<\Psi_{4}<\Psi_{2}$.

As a final observation, in our graphical analysis the vertical distance between the kinked lines $W_{I}^{*}$ and $W_{U}$ for $\Psi=0$ describes the welfare loss that decisionmakers incur when they face the classification risk (see Figure 3).

In this last paragraph we consider the private and social value of information under Disclosure Duty. For the Law of Large Numbers, $W_{I}^{*}$ and $W_{U}$ represent both consumers' (expected) utility and social welfare. Moreover, given the informational structure characterizing Disclosure Duty, the private and social value of information are equivalent.

Corollary 2 (The value of information under Disclosure Duty) Under Disclosure Duty, the private and social value of information are the same. In Equilibrium of Type 1 the value of information is always negative. In Equilibrium of Type 2 the value of information is positive for $\Psi_{3}<\Psi<\Psi_{4}$ and negative for $\Psi<\Psi_{3}$ and $\Psi>\Psi_{4}$.

\subsection{The Consent Law approach}

Under Consent Law decision-makers can secretly take the test before insurance purchase and are then free to show the test result or to conceal it. If they transmit the information provided by the test to insurers, the latter can use such information for rating. Thus, insurers offer contracts contingent on information 


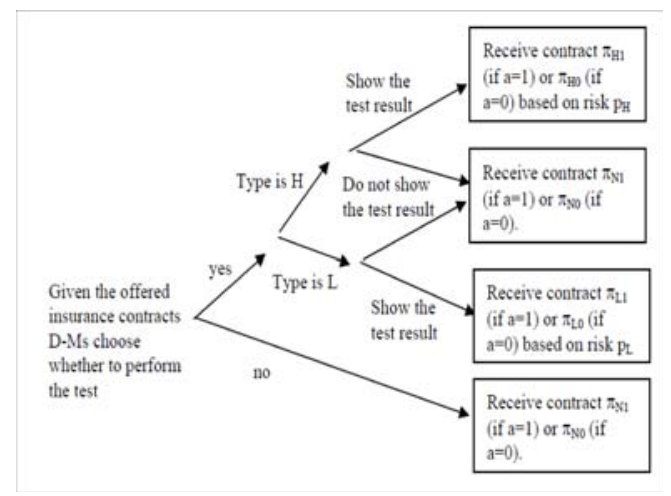

Figure 4: consumers' decision-tree under Consent Law.

that may have been disclosed by consumers. Figure 4 shows the decision-makers' decision tree under Consent Law.

Informed individuals who learn that they are low-types have incentives to show the test result to insurers to buy the policy at a low premium. Individuals who receive bad news, on the other hand, prefer to conceal the test result by pretending to be uninformed. Since insurers are not able to separate (ex-ante) the informed high-risks from the uninformed, they must offer the same contract to both of them (see Figure 4).

In this situation, if decision-makers choose to perform the test, insurance firms can easily screen consumer types by offering full insurance at a fair premium to low-risks who show the test result. Decision-makers pretending to be uninformed are necessarily high-risks and, at the equilibrium, they also receive full insurance at a fair premium. This screening mechanism works only if performing the test is a dominant strategy for uninformed consumers. We show in the proof of the following lemma that decision-makers $d o$ prefer to acquire information if firms offer to uninformed individuals a (partial) insurance contract such that informed high-risks, by accepting such a policy, receive the same utility as they would by showing insurers the test result. The intuition is that, by performing the test, decision-makers can always obtain the same utility as uninformed (when they learn they are high-risk) or they may be able to choose a policy that is strictly preferred (when they learn that they are low-risk).

Lemma 2 (Equilibrium allocation under Consent Law) Under the Consent Law approach, at the equilibrium decision-makers perform the test and show the test result to insurers when they learn that they are low-risk. Both types receive full insurance at a fair premium. ${ }^{13}$

\footnotetext{
${ }^{13}$ The described equilibrium is unique. In fact, no other equilibrium exists where consumers learn information, nor an equilibrium where decision-makers remain uninformed. To see the latter point note that fair full insurance contracts must be offered to people showing the test result, since otherwise new firms would enter the market and make positive profits on low-
} 
Proof. See the Appendix 6.5.

Lemma 2 extends Doherty and Thistle's Proposition 2 (1996) to the case of secondary prevention. Our proof is different, however, since Doherty and Thistle consider a game with simultaneous moves, whereas we assign the first move to insurers. Moreover, in Doherty and Thistle some consumers know their risk ex-ante, whereas here all consumers are ex-ante uninformed.

From the previous discussion: ${ }^{14}$

Corollary 3 (Welfare properties of the equilibrium allocation under Consent Law) When insurance against the classification risk is not available and Consent Law is in place, the equilibrium allocation corresponds to the interim optimal allocation and prevention choices are interim efficient.

Since, under Consent Law, acquiring information is a dominant strategy for decision-makers, the private value of information is positive. As for the social value of information, it corresponds to the difference between welfare in the equilibrium allocation $W_{I}^{*}$ and welfare in the allocation that would emerge when consumers remain uninformed $W_{U} \cdot{ }^{15}$ The following corollary can be stated:

Corollary 4 (The value of information under Consent Law) Under Consent Law (i) the private value of information is positive; (ii) when condition (9) holds, the social value of information is always negative. When the opposite of condition (9) holds, the social value of information is positive for $\Psi_{3}<\Psi<\Psi_{4}$ and negative for $\Psi<\Psi_{3}$ and $\Psi>\Psi_{4}$.

\subsection{The Strict Prohibition approach}

Under Strict Prohibition insurers cannot request any genetic test and cannot use genetic information for rating. This implies that, as under Consent Law, privacy

risks. Moreover, we have already observed that the same policy must be offered to informed consumers not showing the test result and to the uninformed. Thus, remaining uninformed can never be a dominant strategy.

${ }^{14}$ Note that, when the information structure is such that insurers observe decision-makers' information status but not the test result, a different equilibrium allocation arises. In fact, in such a case, different contracts can be offered to informed high-risks and to uninformed decision-makers. Moreover, informed consumers not showing the test result are necessarily high-risks. Thus, both uninformed and informed high-risk consumers receive full coverage at a fair premium (respectively $p_{U} L\left(a_{U}\right)$ and $p_{H} L\left(a_{H}\right)$ ). As a consequence, when deciding whether to learn their type, decision-makers must choose between the allocation for uninformed consumers $W_{U}$ and the interim optimal allocation $W_{I}^{*}$ so that we are back to the equilibria obtained under the Disclosure Duty approach. This proves that, from a social welfare point of view, Disclosure Duty is equivalent to a regulatory scheme assigning privacy to the test result but not to consumers' information status and allowing information transmission on test results from consumers to insurers.

${ }^{15}$ To calculate the social value of information we do not compare the market outcome under Consent Law with the ex-ante optimal allocation. In fact, since the classification risk is not covered in our market (compulsory genetic insurance is not enforced), first-best can never be reached. 
is assigned to consumer information status and to the test result; however, unlike Consent Law, a ban is imposed on information transmission and use. ${ }^{16}$

We prove that, as under the Consent Law approach, information gathering is a dominant strategy for decision-makers. However, here the equilibrium corresponds to the Rothschild-Stiglitz separating allocation. As before, insurers are able to screen consumer types and the information acquired is disclosed at the equilibrium. Unlike the previous case, informed low-risks receive partial insurance.

The Rothschild-Stiglitz separating contracts work as a screening mechanism only if performing the test is a dominant strategy for uninformed consumers. We show in the following lemma that, if firms offer consumers a set of selfselective contracts involving partial insurance at a fair premium, decision-makers will indeed choose to acquire information. In particular, as under Disclosure Duty, insurance firms offer three different types of contract: one for uninformed consumers, one for informed high-risks and one for informed low-risks. However, since the consumers' informational status is private information, here contracts must be self-selecting.

Lemma 3 (Equilibrium allocation under Strict Prohibition) Under the Strict Prohibition approach, decision-makers perform the test. The equilibrium corresponds to the Rothschild-Stiglitz separating allocation.

Proof. See Appendix 6.6.

This result extends Doherty and Thistle's Proposition 1 (1996) to the case of secondary prevention. Again our proof is different since in our model choices are sequential and all decision-makers are ex-ante uninformed. ${ }^{17}$

As regards market outcome under Strict Prohibition we can say the following: ${ }^{18}$

\footnotetext{
${ }^{16}$ The same information structure can also describe a situation where insurers' associations adopt a voluntary moratorium on the use of genetic tests.

${ }^{17}$ The existence of an equilibrium requires the usual Rothschild-Stiglitz condition on the number of low-risks, which must be sufficiently high (Rothschild and Stiglitz 1976). If such condition is not verified we can use different equilibrium concepts such as the Wilson or the Miyazaki equilibrium (see Wilson 1977 and Miyazaki 1977). Both equilibria emerge when the Rothschild-Stiglitz one does not exist. The Wilson equilibrium occurs when insurers can withdraw contracts making negative profits, whereas the Miyazaki equilibrium occurs when insurance companies can offer several contracts involving cross-subsidization. Note that whatever concept of equilibrium we use, the proof in Appendix 6.6 still holds and information gathering remains the consumers' dominant strategy.

${ }^{18}$ Note that, when information structure is such that insurers observe decision-makers' information status but not the test result and a ban on information transmission exists, a different equilibrium occurs. Since contracts can be contingent on consumers' information status, uninformed individuals receive full coverage at a fair premium whereas informed ones receive self-selective (Rothschild-Stliglitz) contracts. As a consequence, when deciding whether to learn information, decision-makers must choose between the allocation for uninformed consumers $W_{U}$ and the lottery assigning full coverage at a high premium with probability $\lambda$ and partial coverage at a low premium with probability $1-\lambda$. This leads to equilibria similar to the ones we obtained with Consent Law under the same informational structure (see footnote 14). However, in the present case, consumers will prefer to remain uninformed more often since here information gathering leads to the Rothschild-Stliglitz equilibrium, that is to a lower welfare.
} 
Corollary 5 (Welfare properties of the equilibrium allocation under Strict Prohibition) When insurance against the classification risk is not available and Strict Prohibition is in place, the equilibrium allocation is such that high-risks receive full insurance at a fair premium, whereas low-risks receive partial insurance at a fair premium. Prevention choices are interim efficient for high-risks, whereas low-risks perform prevention more often than in the interim efficient allocation.

Proof. The first sentence comes directly from Lemma 3. For the last sentence see Appendix 6.7.

We have shown that under Strict Prohibition decision-makers perform the test. Again this implies that the private value of information is positive. As regards the social value of information, we compare the Rothschild-Stiglitz separating allocation and $W_{U}$. The following corollary can be stated:

Corollary 6 (The value of information under Strict Prohibition) Under Strict Prohibition (i) the private value of information is positive; (ii) when condition (9) holds, the social value of information is always negative. When the opposite of condition (9) holds, the social value of information is negative for $\Psi<\Psi_{3}$ and $\Psi>\Psi_{4}$ and is lower than under consent law for $\Psi_{3}<\Psi<\Psi_{4} \cdot{ }^{19}$

We saw that under Consent Law the equilibrium allocation $W_{I}^{*}$ dominates $W_{U}$ only if the opposite of condition (9) holds and prevention costs belong to the interval $\left[\Psi_{3}, \Psi_{4}\right]$. Under Strict Prohibition and when the previous conditions are verified, social welfare is lower than under Consent Law because of the welfare cost paid by (partially insured) low-risks in the Rothschild-Stiglitz equilibrium. This explains the second part of point (ii) in Corollary 6 .

\subsection{The Laissez-Faire approach}

Under the Laissez-Faire approach insurers can request the disclosure of existing tests (as under Disclosure Duty) and they can also request new tests to be performed (and disclosed). Since in our setting consumers are ex-ante uninformed, this regulatory approach implies that insurers decide whether consumers should perform the test or not. Given that the test is costless and useful for rating, insurers will always ask consumers to perform the test. Like disclosure duty, the Laissez-Faire approach implies symmetric information between consumers and insurance firms.

A natural interpretation of the first actions in the timing is the following: insurers ask potential consumers to perform the test and then the test result

\footnotetext{
${ }^{19}$ Contrary to us, Doherty and Posey (1998) find that the social value of information is always positive when information structure corresponds to Strict Prohibition. This difference essentially depends on the fact that, in their model, part of the consumers are ex-ante informed. Thus, to evaluate the social value of information, they compare the equilibrium allocation (where all consumers become informed) with the allocation that would arise without information gathering (where the uninformed remain uninformed and informed consumers receive the Rothschild-Stiglitz separating contracts).
} 
is disclosed to both consumers and insurers. ${ }^{20}$ The consequence is that, under Laissez-Faire, insurers offer full insurance contracts at a fair premium to highand low-types.

Lemma 4 (Equilibrium allocation under Laissez-Faire) Under the LaissezFaire approach the equilibrium allocation corresponds to the interim efficient allocation and prevention actions are interim efficient.

Since under Laissez-Faire insurance firms require consumers to perform the test, the private value of information has no meaning. As regards the social value of information, as under Consent Law, we must compare allocations $W_{I}^{*}$ and $W_{U}$. Thus, part (ii) in Corollary 4 also applies to the Laissez-Faire approach.

\section{A comparison of the alternative regulatory approaches}

We now compare the different regulatory approaches analyzed before and derive a complete ranking. From the four previous lemmas we can state the following:

Proposition 1 (Welfare comparison of the alternative regulatory approaches) From a social welfare point of view the Disclosure Duty approach weakly dominates all the other regulatory schemes. The Laissez-Faire and the Consent Law approaches lead to the same equilibrium allocation. The equilibrium allocation under Strict Prohibition is dominated by all the other regulatory schemes.

In the rest of this section first we summarize our results as regards prevention choices and then as regards information disclosure at the different equilibria.

Under the Laissez-Faire and the Consent Law approaches prevention choices are interim efficient. With Strict Prohibition they are interim efficient for highrisks, whereas low-risks choose prevention under partial insurance. This implies that low-risks perform prevention more often under Strict Prohibition than in the interim efficient allocation. Under Disclosure Duty prevention choices are interim efficient only in Equilibrium of Type 2 for prevention costs belonging to the interval $\left[\Psi_{3}, \Psi_{4}\right]$. Importantly in such a specific case, Disclosure Duty, Laissez-Faire and Consent Law all lead to the same equilibrium allocation and therefore to the same social welfare, whereas in all the other cases disclosure duty strongly dominates the other regulatory schemes even though it leads to less efficient prevention choices. Note that the effectiveness of secondary prevention, the magnitude of the classification risk as well as the cost of prevention all

\footnotetext{
${ }^{20}$ Note that, if the order of the first two actions in the timing were the same as before (first insurers offer contracts, then they ask consumers to perform the test and the test result is disclosed), the first best allocation would be obtained. In fact, in such a case the insurance contract offered by insurers would also cover the classification risk. However, since in the real world the classification risk is not covered, we exclude such a sequence of actions.
} 
affect the decision to gather information under Disclosure Duty and therefore the possibility of Equilibrium of Type 2 occurring. ${ }^{21}$

As a final observation Laissez-Faire, Consent Law and Strict Prohibition always lead to information disclosure at the equilibrium. Disclosure Duty, again, leads to information disclosure only in Equilibrium of Type 2 and for intermediate values of prevention costs.

In general, either the informational structure is such that insurers observe the test result, if any (as in the Laissez-Faire and in the Disclosure Duty approach), or insurers learn information on consumer risks ex-post by using self-selective contracts. Basically, under Consent Law information is transmitted at no cost by low-risks showing insurers the test result. Under Strict Prohibition, on the other hand, screening requires a welfare cost since self-selecting contracts provide partial insurance to the low-risks. Put differently, Strict Prohibition is the only regulatory scheme which endogenously produces standard adverse selection.

\section{Conclusion}

In this paper we contribute to the literature on genetic testing by (i) introducing secondary prevention measures which assign decision-making value to genetic information and by (ii) providing a welfare analysis of the alternative schemes used to regulate genetic information. In particular, we investigate the four main regulatory approaches we find today in health insurance markets: Laissez-Faire, Disclosure Duty, Consent Law and Strict Prohibition. Our simple and tractable model allows for unambiguous ranking.

In our model consumers may gather information on their risk of illness before insurance policy purchase. Insurance firms offer policies covering the risk of the monetary loss associated with the illness but not the classification risk. We put ourselves in a context which seems more natural when considering information provided by genetic testing: we assume that all consumers are ex-ante uninformed and that information allows better choices as regards secondary prevention.

Our model makes some assumptions that could be worth relaxing in the future. Genetic tests have no cost and consumer prevention choices are observable by insurance firms. However, the first assumption is common to almost all the literature on genetic testing ${ }^{22}$ and the second one is plausible for secondary prevention, which indicates a certifiable medical procedure.

\footnotetext{
${ }^{21}$ For example we expect Equilibrium of Type 1 to occur under Disclosure Duty in the case of genetic test for Huntington's disease since, for such an illness, classification risk is high and early detection of disease is ineffective. Thus, Disclosure Duty should strongly dominate the other regulatory schemes as regards testing for Huntington's disease whereas Equilibrium of Type 2 could occur under Disclosure Duty in the case of tests detecting BRCA1, BRCA2 or HNPCC genetic mutations since, for the illnesses related to those mutations, effective secondary prevention exists. Thus, for those tests and for some values of prevention costs, Disclosure Duty could be equivalent to Consent Law and Laissez-Faire.

${ }^{22}$ An exception is Doherty and Thistle (1996).
} 
Our results show that market and health authorities aiming at maximizing consumers' welfare should implement a mild type of regulation such as the Disclosure Duty scheme. With this regulatory approach consumers are free to decide whether to perform genetic tests but have no privacy rights on information status and on test results. We have proved that only under Disclosure Duty consumers remain uninformed when the cost imposed by the classification risk prevails over the benefit of information in terms of better prevention measures, that is, when gathering information is not efficient.

The result that the insurance market performs better under mild regulation than under strong regulation of genetic information is not new. In different models Hoel and Iversen (2002) and Hoel et al. (2006) reached the same conclusion. ${ }^{23}$ What clearly emerges from our analysis is that Strict Prohibition, the most widespread regulatory approach, adopted with the explicit objective of increasing consumers' welfare by avoiding genetic discrimination, leads to the worst market outcome from a consumer welfare point of view. Strict Prohibition assigns consumer privacy on information status and test result and bans information transmission from consumers to insurers. Such a ban turns out to be detrimental to consumer welfare because it leads to adverse selection and thus prevents efficient exchange in the health insurance market. Consent Law performs better than Strict Prohibition because it assigns consumers both privacy on genetic information and control rights on information provided by the test. More generally, privacy on genetic information turns out to be of no use in preventing discrimination since under both Consent Law and Strict Prohibition insurance firms adopt screening devices such that information is fully disclosed at the equilibrium.

To conclude, governments aiming at protecting "bad genetic risks" from discrimination should not impose strict regulation of genetic information; they should instead opt for a Disclosure Duty rule and then provide a specific public program, or expand the existing ones, offering (subsidized) insurance coverage for the high-risks. ${ }^{24}$ Even better, governments should try to create the missing market for "genetic insurance", as proposed by Tabarrok (1994). In this regard our model characterizes the welfare loss due to the lack of coverage against the classification risk and clearly states the importance of "genetic insurance" provision. We believe that it would be interesting to formally investigate reasons why, in the real world, insurance markets are not able to provide coverage for the classification risk. We leave this issue to future research.

\footnotetext{
${ }^{23}$ In Hoy and Ruse (2005) the decision whether to gather information is not endogenous, however the authors stress the inefficiencies due to adverse selection arising when privacy on genetic information is assigned to consumers.

${ }^{24}$ Possible redistributional policies aimed at remedying existing inequality in health risk and in insurance premium produced by genetic testing are analyzed in Rees and Apps (2006).
} 


\section{Appendix}

\subsection{Proof of Remark 2}

(i) When $p_{L} \geq \frac{\Psi}{\Delta_{0}}$ the optimal action for low-type decision-makers corresponds to a positive level of prevention: $\widehat{a}\left(p_{L}\right)=1$. Given inequality 1 , this implies: $\widehat{a}\left(p_{U}\right)=\widehat{a}\left(p_{H}\right)=1$, and, $\widehat{V}\left(p_{U}\right)=\lambda \widehat{V}\left(p_{H}\right)+(1-\lambda) \widehat{V}\left(p_{L}\right)$. Whereas when $p_{H} \leq \frac{\Psi}{\Delta_{0}}$ the optimal action for high-type decision-makers corresponds to noprevention: $\widehat{a}\left(p_{H}\right)=0$. Thus, $\widehat{a}\left(p_{U}\right)=\widehat{a}\left(p_{L}\right)=0$ and, again, $\widehat{V}\left(p_{U}\right)=\lambda \widehat{V}\left(p_{H}\right)+$ $(1-\lambda) \widehat{V}\left(p_{L}\right)$. (ii) Suppose first that $p_{L}<p_{U} \leq \frac{\Psi}{\Delta_{0}}<p_{H}$. When uninformed, decision-makers do not exert prevention such that $\widehat{V}\left(p_{U}\right)=p_{U} u(w-L)+(1-$ $\left.p_{U}\right) u(w)$. If decision-makers acquire information, given again inequality 1 , their expected utility becomes:

$$
\begin{aligned}
\lambda \widehat{V}\left(p_{H}\right)+(1-\lambda) \widehat{V}\left(p_{L}\right) & =\lambda\left(p_{H} u(w-l)+\left(1-p_{H}\right) u(w)-\Psi\right) \\
& +(1-\lambda)\left(p_{L} u(w-L)+\left(1-p_{L}\right) u(w)\right) \\
& =\lambda p_{H} u(w-l)+(1-\lambda) p_{L} u(w-L)+\left(1-p_{U}\right) u(w)-\lambda \Psi
\end{aligned}
$$

Using 1 it is easy to verify that $\widehat{V}\left(p_{U}\right)<\lambda \widehat{V}\left(p_{H}\right)+(1-\lambda) \widehat{V}\left(p_{L}\right)$. Suppose now that $p_{L}<\frac{\Psi}{\Delta_{0}} \leq p_{U}<p_{H}$. Here uninformed consumers choose prevention and $\widehat{V}\left(p_{U}\right)=p_{U} u(w-l)+\left(1-p_{U}\right) u(w)-\Psi$. By comparing $\widehat{V}\left(p_{U}\right)$ and $\lambda \widehat{V}\left(p_{H}\right)+$ $(1-\lambda) \widehat{V}\left(p_{L}\right)$ it is easy to verify that, again, $\widehat{V}\left(p_{U}\right)<\lambda \widehat{V}\left(p_{H}\right)+(1-\lambda) \widehat{V}\left(p_{L}\right)$.

\subsection{Proof of Remark 3}

(i) It comes directly from the discussion above Remark 3. (ii) It is easy to prove that $\Delta\left(p_{i}\right)$ is an increasing function. In fact, $\frac{\partial \Delta\left(p_{i}\right)}{\partial p_{i}}=-l u^{\prime}\left(w-p_{i} l\right)+L u^{\prime}(w-$ $\left.p_{i} L\right)$ which is positive since $L>l \geq 0$ and $u^{\prime}\left(w-p_{i} L\right)>u^{\prime}\left(w-p_{i} l\right) \geq 0$. (iii) Inequality (1) is the condition for positive prevention without insurance and can be written as $p_{i} \Delta_{0} \geq \Psi$. We compare inequality (1) with (2), and we prove that $\Delta\left(p_{i}\right) \leq p_{i} \Delta_{0}$. The latter inequality can be rewritten as $u\left(w-p_{i} l\right)-p_{i} u(w-$ $l) \leq u\left(w-p_{i} L\right)-p_{i} u(w-L)$. Let $f(x)=u\left(w-p_{i} x\right)-p_{i} u(w-x) . f^{\prime}(x)=$ $-p_{i} u^{\prime}\left(w-p_{i} x\right)+p_{i} u^{\prime}(w-x)$ be positive as soon as $0 \leq p_{i} \leq 1$ and $u$ concave. Then $f$ is increasing and $u\left(w-p_{i} l\right)-p_{i} u(w-l)=f(l) \leq f(L)=u\left(w-p_{i} L\right)$ $-p_{i} u(w-L)$.

\subsection{Proof of Remark 5}

We start with the proof of (ii). Functions $W_{I}^{*}$ and $W_{U}$ cross each other twice if $W_{I}^{*}$ calculated in $\Psi=\Delta\left(p_{U}\right)$ is larger than $W_{U}=u\left(w-p_{U} L\right)$ (see Figure 3 ); this writes:

$$
\lambda u\left(w-p_{H} l\right)+(1-\lambda) u\left(w-p_{L} L\right)-\lambda \Delta\left(p_{U}\right)>u\left(w-p_{U} L\right)
$$

Substituting $\Delta\left(p_{U}\right)=u\left(w-p_{U} l\right)-u\left(w-p_{U} L\right)$ and rearranging inequality (10), the opposite of condition (9) can be easily found. $\Psi_{3}$ is the value on the left of 
$\Delta\left(p_{U}\right)$ such that $W_{I}^{*}=u\left(w-p_{U} l\right)-\Psi$, whereas $\Psi_{4}$ is the value on the right of $\Delta\left(p_{U}\right)$ such that $W_{I}^{*}=u\left(w-p_{U} L\right)$. (i) It comes immediately from (ii).

\subsection{Proof of Remark 6}

Let's substitute $p_{H}-p_{U}=(1-\lambda)\left(p_{H}-p_{L}\right)$ and $p_{U}-p_{L}=\lambda\left(p_{H}-p_{L}\right)$ in the l.h.s. of (9) and call $p_{H}-p_{L}=x$. We can therefore rewrite the l.h.s. of (9) as a function of $x$ :

$$
\Gamma_{u}(x)=\frac{\frac{\left[u\left(w-p_{U} l\right)-u\left(w-p_{U} l-(1-\lambda) l x\right)\right]}{(1-\lambda) l}}{\frac{\left[u\left(w-p_{U} L+\lambda L x\right)-u\left(w-p_{U} L\right)\right]}{\lambda L}}
$$

Because of the concavity of $u, \Gamma$ is an increasing function such that:

$$
\Gamma_{u}(0)=\frac{u^{\prime}\left(w-p_{U} l\right)}{u^{\prime}\left(w-p_{U} L\right)} \leq 1 .
$$
if:

Moreover, substituting $\Gamma_{u}(x)$ in condition (9), $W_{I}^{*}$ and $W_{U}$ cross each other

$$
\Gamma_{u}\left(p_{H}-p_{L}\right) \leq \frac{L}{l}
$$

Putting together (11) and (12):

$$
0 \leq p_{H}-p_{L} \leq \Gamma_{u}^{-1}\left(\frac{L}{l}\right) .
$$

\subsection{Proof of Lemma 2}

The proof is organized in two steps. First we show that, at the equilibrium, decision-makers perform the test when insurance firms offer full-insurance contracts; we then show that the result does not change when firms are free to offer partial-insurance contracts.

(i) Full-insurance contracts. Suppose that firms are constrained to offer full-insurance contracts. Insurers ex-ante propose 4 full-insurance contracts contingent on the decision-maker's action and on the test result if decision-makers decide to show it, and 2 full-insurance contracts only contingent on the preventative action if decision-makers do not show the test result. The insurance premiums are:

\begin{tabular}{|l|l|l|}
\hline & with prevention & without prevention \\
\hline Show result L & $\pi_{L 1}=p_{L} l$ & $\pi_{L 0}=p_{L} L$ \\
\hline Show result H & $\pi_{H 1}=p_{H} l$ & $\pi_{H 0}=p_{H} L$ \\
\hline Don't show & $\pi_{N 1}$ & $\pi_{N 0}$ \\
\hline
\end{tabular}

We are looking for an equilibrium where decision-makers perform the test and show the test result to insurers when the test reveals good news. For this equilibrium to exist, we have necessarily $p_{H} l \geq \pi_{N 1} \geq p_{L} l$ and $p_{H} L \geq \pi_{N 0} \geq$ $p_{L} L$. 
When deciding whether to perform the test or not, decision-makers must compare:

$\lambda \max \left\{u\left(w-\pi_{N 1}\right)-\Psi, u\left(w-\pi_{N 0}\right)\right\}+(1-\lambda) \max _{a_{L}}\left(u\left(w-p_{L} L\left(a_{L}\right)\right)-\Psi\left(a_{L}\right)\right)$

with:

$$
\max \left\{u\left(w-\pi_{N 1}\right)-\Psi, u\left(w-\pi_{N 0}\right)\right\},
$$

where (13) is expected utility when the test is performed: with probability $\lambda$ the decision-maker is high-risk, does not show the test result and chooses the maximum between full-insurance with prevention and full-insurance without prevention; with probability $1-\lambda$ the decision-maker is low-risk, shows the test result and maximizes his full-insurance utility with respect to the action, whereas (14) is utility when decision-makers remain uninformed.

We now show that expected utility with the test (13) is higher than expected utility without the test (14). Suppose it is not. Then it must necessarily be:

$$
\max \left(u\left(w-\pi_{N 1}\right)-\Psi, u\left(w-\pi_{N 0}\right)\right) \geq \max _{a_{L}} u\left(w-p_{L} L\left(a_{L}\right)\right)-\Psi\left(a_{L}\right)
$$

then nobody performs the test and $\pi_{N 1}=p_{U} l, \pi_{N 0}=p_{U} L$. However this is impossible since:

$$
\max _{a_{L}} u\left(w-p_{L} L\left(a_{L}\right)\right)-\Psi\left(a_{L}\right)>\max _{a_{U}} u\left(w-p_{U} L\left(a_{U}\right)\right)-\Psi\left(a_{U}\right)
$$

We proved that it must be:

$$
\max \left(u\left(w-\pi_{N 1}\right)-\Psi, u\left(w-\pi_{N 0}\right)\right) \leq \max _{a_{L}} u\left(w-p_{L} L\left(a_{L}\right)\right)-\Psi\left(a_{L}\right)
$$

This implies that expected utility with the test (13) dominates utility without the test (14) and decision-makers prefer to gather information.

We can conclude that the allocation where uninformed decision-makers perform the test and show it to insurers only when they learn to be low-types is an equilibrium. Thus, at the equilibrium, all decision-makers not showing the test are high-risk such that $\pi_{N 1}=p_{H} l$ and $\pi_{N 0}=p_{H} L$ : both high- and low-risks receive full insurance at a fair premium.

(ii) Partial-insurance contracts. Suppose now that insurance companies can propose ex-ante self-selective contracts with partial coverage. In this case, firms will offer full-insurance contracts for those who show the test result and a contract with partial coverage for those who declare that they are uninformed. Let's call $y$ or $Y$ the partial coverage according to whether decision-makers choose prevention or not. As a result we obtain the set of contracts illustrated in the following table:

\begin{tabular}{|l|l|l|}
\hline & with prevention & without prevention \\
\hline Show result L & $\pi_{L 1}=p_{L} l$, full coverage & $\pi_{L 0}=p_{L} L$, full coverage \\
\hline Show result $\mathrm{H}$ & $\pi_{H 1}=p_{H} l$, full coverage & $\pi_{H 0}=p_{H} L$, full coverage \\
\hline Don't show & $p_{U} y$, partial coverage & $p_{U} Y$, partial coverage \\
\hline
\end{tabular}


To be self-selecting the proposed partial-insurance contracts must be such that informed high-types are indifferent between showing the test result and thus obtaining full insurance at a fair premium and pretending to be uninformed and thus obtaining partial insurance, i.e.:

$$
\begin{aligned}
u\left(w-p_{H} L\right) & \left.=p_{H} u\left(w-p_{U} Y+Y-L\right)+\left(1-p_{H}\right) u\left(w-p_{U} Y\right)=U_{H}(1) 乃\right) \\
u\left(w-p_{H} l\right) & =p_{H} u\left(w-p_{U} y+y-l\right)+\left(1-p_{H}\right) u\left(w-p_{U} y\right)=U_{H}(y)
\end{aligned}
$$

where $U_{H}(Y)$ is expected utility for high-risks under partial insurance and without prevention and $U_{H}(y)$ is expected utility gross of prevention cost under partial insurance and with prevention.

Suppose now that uninformed consumers perform the test. When the test result is $p_{L}$ decision-makers show it to insurers and receive full insurance at a fair premium. When the test result is $p_{H}$ decision-makers are indifferent between showing the test result and pretending to be uninformed according to equations (15) and (16). Assume that, when indifferent, high-risks show the test result to insurers and receive full insurance at a fair premium too.

As a consequence, performing the test gives:

$$
\begin{aligned}
W_{I}^{*} & =\lambda u\left(w-p_{H} L\left(\hat{a}_{H}\right)\right)+(1-\lambda) u\left(w-p_{L} L\left(\hat{a}_{L}\right)\right)-\lambda \Psi\left(\hat{a}_{H}\right)-(1-\lambda) \Psi\left(\hat{a}_{L}\right) \\
& =\lambda W_{H}^{*}+(1-\lambda) W_{L}^{*}
\end{aligned}
$$

where:

$$
W_{L}^{*}=\max \left(u\left(w-p_{L} L\right), u\left(w-p_{L} l\right)-\Psi\right)
$$

and, for construction:

$$
W_{H}^{*}=\max \left(U_{H}(Y), U_{H}(y)-\Psi\right)=\max \left(u\left(w-p_{H} L\right), u\left(w-p_{H} l\right)-\Psi\right)
$$

Let's now consider expected utility, gross of prevention cost, obtained by lowrisks when they stay uninformed, receive the partial insurance contract and perform prevention:

$$
\begin{aligned}
U_{L}(y) & =p_{L} u\left(w-p_{U} y+y-l\right)+\left(1-p_{L}\right) u\left(w-p_{U} y\right) \\
& <u\left(p_{L}\left(w-p_{U} y+y-l\right)+\left(1-p_{L}\right)\left(w-p_{U} y\right)\right) \\
& =u\left(w-p_{L} l-\left(p_{U}-p_{L}\right) y\right) \\
& <u\left(w-p_{L} l\right)
\end{aligned}
$$

In the same way let's consider expected utility obtained by low-risks when they stay uninformed, receive the partial insurance contract and do not perform prevention. $^{25}$ The following holds:

$$
U_{L}(Y)<u\left(w-p_{L} L\right)
$$

\footnotetext{
${ }^{25}$ Note that in proof (i), the premium for those who declare that they are uninformed was constrained by the full coverage $l$ (or $L$ ). Thus, the probability in such a premium was necessarily the equilibrium probability (or the type of those who declare that they are uninformed at the equilibrium). Here, on the contrary, because of partial insurance a degree of freedom exists as regards the premium for those who declare that they are uninformed. Thus, any probability can be chosen in the premium, provided that the coverage is the equilibrium coverage $y(Y)$ given by equations (16) and (15). In the proof we have taken probability $p_{U}$ because the latter allows inequalities (20) and (21) to be easily obtained.
} 
Inequalities (20) and (21) imply that low-risks receive a larger utility when they obtain full insurance at a fair premium then when they stay uninformed and obtain the partial insurance contract. This writes:

$$
W_{L}^{*}>\max \left(U_{L}(Y), U_{L}(y)-\Psi\right)
$$

Finally, by remaining uninformed, decision-makers get:

$$
\begin{aligned}
& \max \left(U_{U}(Y), U_{U}(y)-\Psi\right) \\
= & \max \left(\lambda U_{H}(Y)+(1-\lambda) U_{L}(Y), \lambda U_{H}(y)+(1-\lambda) U_{L}(y)-\Psi\right)
\end{aligned}
$$

Now we can compare (17) and (23) taking into account (19) and (22). We find:

$$
\lambda W_{H}^{*}+(1-\lambda) W_{L}^{*}>\max \left(U_{U}(Y), U_{U}(y)-\Psi\right)
$$

so that uninformed decision-makers strictly prefer to take the test.

\subsection{Proof of Lemma 3}

As $p_{L} \leq p_{U} \leq p_{H}$, the problem is formally equivalent to a 3-type RothschildStiglitz model. At the equilibrium, firms offer a set of self-selective contracts involving partial insurance at a fair premium. Let's denote $x(a), y(a)$ and $z(a)$ the offered coverages when the level of prevention is $a$ according to the following table:

\begin{tabular}{|l|c|}
\hline & coverage and premium \\
\hline Type H & $z(a), p_{H} z(a)$ \\
\hline Uninformed & $y(a), p_{U} y(a)$ \\
\hline Type L & $x(a), p_{L} x(a)$ \\
\hline
\end{tabular}

Let's call $U_{i}(\alpha, \beta, a)=p_{i} u(w-L(a)+\alpha-\beta)+\left(1-p_{i}\right) u(w-\beta)-\Psi(a)$ type- $i$ expected utility with coverage $\alpha$, premium $\beta$ and action $a$, where $\alpha=$ $z(a), y(a), x(a) ; \beta=p_{H} z(a), p_{U} y(a), p_{L} x(a) ; i=H, U, L$ and $a=0$ or 1.

To be self-selecting, the insurers' offer must fulfill:

$$
\begin{aligned}
& U_{H}\left(z(a), p_{H} z(a), a\right) \geq U_{H}\left(y(a), p_{U} y(a), a\right) \\
& U_{H}\left(z(a), p_{H} z(a), a\right) \geq U_{H}\left(x(a), p_{L} x(a), a\right) \\
& U_{U}\left(y(a), p_{U} y(a), a\right) \geq U_{U}\left(z(a), p_{H} z(a), a\right) \\
& U_{U}\left(y(a), p_{U} y(a), a\right) \geq U_{U}\left(x(a), p_{L} x(a), a\right) \\
& U_{L}\left(x(a), p_{L} x(a), a\right) \geq U_{L}\left(y(a), p_{U} y(a), a\right) \\
& U_{L}\left(x(a), p_{L} x(a), a\right) \geq U_{L}\left(z(a), p_{H} z(a), a\right)
\end{aligned}
$$

To decide whether to perform the test, an ex-ante uninformed individual must compare $\max \left(U_{U}\left(y(a), p_{U} y(a), a\right)\right)$, with :

$$
\lambda \max _{a}\left(U_{H}\left(z(a), p_{H} z(a), a\right)\right)+(1-\lambda) \max _{a}\left(U_{L}\left(x(a), p_{L} x(a), a\right)\right)
$$


As the set of contracts is self-selective, we have:

$$
\begin{aligned}
U_{H}\left(z(a), p_{H} z(a), a\right) & \geq U_{H}\left(y(a), p_{U} y(a), a\right) \\
U_{L}\left(x(a), p_{L} x(a), a\right) & \geq U_{L}\left(y(a), p_{U} y(a), a\right)
\end{aligned}
$$

and then:

$$
\begin{aligned}
& \lambda \max _{a}\left(U_{H}\left(z(a), p_{H} z(a), a\right)\right)+(1-\lambda) \max _{a}\left(U_{L}\left(x(a), p_{L} x(a), a\right)\right) \\
\geq & \lambda \max _{a}\left(U_{H}\left(y(a), p_{U} y(a), a\right)\right)+(1-\lambda) \max _{a}\left(U_{L}\left(y(a), p_{U} y(a), a\right)\right) \\
\geq & \max _{a}\left(\lambda U_{H}\left(y(a), p_{U} y(a), a\right)+(1-\lambda) U_{L}\left(y(a), p_{U} y(a), a\right)\right) \\
= & \max _{a}\left(U_{U}\left(y(a), p_{U} y(a), a\right)\right)
\end{aligned}
$$

This implies that, ex-ante, gathering information is a dominant strategy for decision-makers whatever the set of self-selective contracts proposed by the insurers.

It follows that the only possible equilibrium is the 2-type Rothschild-Stiglitz separating allocation with $z(a)=L\left(\hat{a}_{H}\right)$ and $x(a)<L\left(\hat{a}_{L}\right)$.

\subsection{Proof of Corollary 5}

We must show that low-risks have more incentives to perform prevention in the Rothschild-Stiglitz equilibrium than in the interim efficient allocation. At the equilibrium, low-risks perform prevention if the following inequality holds:

$$
\begin{gathered}
p_{L} u\left(w-p_{L} x+x-l\right)+\left(1-p_{L}\right) u\left(w-p_{L} x\right)-\Psi \geq \\
p_{L} u\left(w-p_{L} X+X-L\right)+\left(1-p_{L}\right) u\left(w-p_{L} X\right)
\end{gathered}
$$

where $x$ and $X$ are partial insurance coverages for informed low-risks respectively when they choose prevention and when they do not. From Remark 3 (point (iii)) we know that, given a risk $p_{i}$, incentives to perform prevention under full insurance are lower than without insurance. For a continuity argument it follows that low-risks' incentives to perform prevention under full insurance are lower than under partial insurance.

\section{References}

[1] Bennardo A. (2008), "Information gathering, disclosure and contracting in competitive markets", working paper CSEF 190.

[2] Cochrane J.H. (1995), "Time-consistent health insurance", the Journal of Political Economy, 103(3), pp. 445-473.

[3] Cremer J. and F. Khalil, (1992), "Gathering Information before Signing a Contract", The American Economic Review, 82(3), pp. 566-78. 
[4] Crocker K.J. and A. Snow (1992), "The social value of hidden information in adverse selection economies", Journal of Public Economics 48, 317-347.

[5] Doherty, N.A. and L. Posey (1998), "On the value of a checkup: adverse selection, moral hazard and the value of information", The Journal of Risk and Insurance, 65(2), pp. 189-211.

[6] Doherty, N.A. and P.D. Thistle (1996), "Adverse selection with endogenous information in insurance markets", Journal of Public Economics 63, pp. 83102.

[7] The European Commission (2004), "25 Recommendations on the Ethical, Legal, and Social Implications of Genetic Testing", European Commission, Brussels. Available at http://ec.europa.eu/research/conferences/2004/genetic/pdf/recommendations_en.pdf

[8] Hirshleifer J. 1971, "The Private and Social Value of Information and the Reward to Incentive Activity", The American Economic Review, 61, pp. 561-74.

[9] Hoel M. and Iversen T. (2002), "Genetic testing when there is a mix of compulsory and voluntary health insurance", Journal of Health Economics 21, pp. 253-270.

[10] Hoel M. and Iversen T, Nilssen T. and Vislie J. (2006), "Genetic testing in competitive insurance markets with repulsion from chance: A welfare analysis", Journal of Health Economics 25, pp. 847-860.

[11] Hoy M. and Polborn M. (2000), "The value of genetic information in the life insurance market", Journal of Public Economics, 78, pp. 235-252.

[12] Hoy M. and M. Ruse (2005), "Regulating genetic information in insurance markets", Risk Management and Insurance Review 8, pp. 211-237.

[13] Hoy M. and J. Witt (2007), "Welfare effects of banning genetic information in the life insurance markets: the case of BRCA1/2 gens", Journal of Risk E Insurance, Vol. 74, No. 3, pp. 523-546.

[14] Miyazaki H. (1977), "The Rat Race and Internal Labour Market", Bell Journal of Economics 8, pp. 394-418.

[15] Posner R.A. (1981), "The economics of privacy", The American Economic Review, 71(2), pp. 405-409.

[16] Rees R. and P. Apps (2006), "Genetic testing, income distribution and insurance markets", Les Annales d'Economie et de Statistique, 83-84, pp. 295-325.

[17] Rothschild, M. and J. Stiglitz (1976), "Equilibrium in Insurance Markets: an essay on the economics of imperfect information", Quarterly Journal of Economics 90, pp. 629-649. 
[18] Stigler G.J. (1980), "An introduction to privacy in economics and politics", The Journal of Legal Studies, 9(4), pp. 623-644.

[19] Strohmenger R. and A. Wambach (2000), "Adverse selection and categorical discrimination in the health insurance markets: the effects of genetic tests", Journal of Health Economics 19, pp. 197-218.

[20] Tabarrok A. (1994), "Genetic testing: an economic and contractarian analysis", Journal of Health Economics 13, pp. 167-207.

[21] Viswanathan, Krupa S., Lemaire, Jean, Withers, Kate, Armstrong, Katrina, Baumritter, Agnieszka, Hershey, John C., Pauly, Mark V. and Asch, David A. (2007), "Adverse Selection in Term Life Insurance Purchasing Due to the BRCA1/2 Genetic Test and Elastic Demand". Journal of Risk E Insurance, Vol. 74, No. 1, pp. 65-86.

[22] Wilson C. (1977), "A Model of Insurance with Incomplete Information", Journal of Economic Theory, 16: pp. 167-207. 